\title{
Predicting prognosis in stable angina-results from the Euro heart survey of stable angina: prospective observational study
}

Caroline A Daly, Bianca De Stavola, Jose L Lopez Sendon, Luigi Tavazzi, Eric Boersma, Felicity Clemens, Nicholas Danchin, Francois Delahaye, Anselm Gitt, Desmond Julian, David Mulcahy, Witold Ruzyllo, Kristian Thygesen, Freek Verheugt, Kim M Fox, on behalf of the Euro Heart Survey Investigators

\begin{abstract}
Objectives To investigate the prognosis associated with stable angina in a contemporary population as seen in clinical practice, to identify the key prognostic features, and from this to construct a simple score to assist risk prediction.

Design Prospective observational cohort study.

Setting Pan-European survey in 156 outpatient cardiology clinics.

Participants 3031 patients were included on the basis of a new clinical diagnosis by a cardiologist of stable angina with follow-up at one year.

Main outcome measure Death or non-fatal myocardial infarction.

Results The rate of death and non-fatal myocardial infarction in the first year was 2.3 per 100 patient years; the rate was 3.9 per 100 patient years in the subgroup $(n=994)$ with angiographic confirmation of coronary disease. The clinical and investigative factors most predictive of adverse outcome were comorbidity, diabetes, shorter duration of symptoms, increasing severity of symptoms, abnormal ventricular function, resting electrocardiogaphic changes, or not having any stress test done. Results of non-invasive stress tests did not significantly predict outcome in the population who had tests done. A score was constructed using the parameters predictive of outcome to estimate the probability of death or myocardial infarction within one year of presentation with stable angina. Conclusions A score based on the presence of simple, objective clinical and investigative variables makes it possible to discriminate effectively between very low risk and very high risk patients and to estimate the probability of death or non-fatal myocardial infarction over one year.
\end{abstract}

\section{Introduction}

Prognostic assessment is a crucial component of clinical assessment at all levels of care in cardiovascular disease. Although stable angina is the most prevalent manifestation of coronary disease, affecting up to $5 \%$ of the adult population aged over 40 in most developed countries, ${ }^{12}$ contemporary information on the prognosis of the condition is relatively sparse.

To ensure their reliability, risk prediction models may need to be modified according to the population to which they are applied and regularly updated. ${ }^{3}$ The Framingham model, a well constructed and validated risk prediction algorithm based on epidemiological data updated with refreshed intake in the 1970s, has been shown to overestimate risk when applied in contempo- rary European populations. ${ }^{5}{ }^{6}$ These principles apply in similar measure to prediction of risk in populations with stable symptoms, where predictive models are less often applied.

The aims of this investigation were to ascertain the prognosis associated with a clinical diagnosis of stable angina in a contemporary setting; to determine the clinical and investigative factors predictive of death or myocardial infarction; and to construct a simple, user friendly risk prediction model to assist in prognostic evaluation of stable angina.

\section{Methods}

The Euro heart survey of stable angina was designed as a prospective observational cohort study of patients presenting to cardiology services with stable angina. Participating centres were a mix of academic and non-academic institutions, and hospitals with and without interventional and cardiac surgical facilities. The 3031 patients included in the survival analysis were enrolled from 156 centres in 34 countries. The number of patients included in each centre ranged from 1 to 106 , with a median of 17 patients and interquartile range of 8 to 22 . The number of centres in each country ranged from 1 to 27 , with a median of 2 and an interquartile range of 1 to 6 . Further details of centres, data collection, and patient population have previously been described. $^{7}$

\section{Patient population and follow-up}

Briefly, patients attending cardiology services with a new presentation of stable angina were considered for enrolment, and consecutive patients in whom the cardiologist made a clinical diagnosis of stable angina caused by myocardial ischaemia due to coronary disease were included in the survey. All patients gave informed consent. We defined a new presentation as a first ever presentation to a cardiologist or a new referral or re-referral after a period of at least one year of not consulting a cardiologist. Exclusion criteria included unstable angina, admission to hospital within 24 hours of assessment, myocardial infarction within one year, previous revascularisation, or a cause of angina other than coronary disease. Follow-up was done by clinical review or telephone contact as close as possible to one year from initial assessment. The occurrence and dates of occurrence of death or cardiovascular events were recorded, as well as the cause of death if available. The local investigators adjudicated clinical end points

Appendices $A$ and $B$ are on bmj.com 
according to the definitions in appendix A on bmj.com. Severity of angina was assessed by using the Canadian Cardiovascular Society classification. Known cardiovascular risk factors and comorbid conditions were defined as in appendix A.

\section{Statistical analysis}

We used descriptive statistics to estimate the prevalence of risk factors, baseline clinical characteristics, and treatment at presentation. We used Student's $t$ test or analysis of variance as appropriate to test for significant differences in quantitative measures and the $\chi^{2}$ test to test for significant differences in proportions. The primary outcome of interest was the occurrence of death or non-fatal myocardial infarction. In the analysis of the primary outcome we defined follow-up time from enrolment into the study to the time of the first event (death or non-fatal myocardial infarction) or 18 months after recruitment. Follow-up was censored at 18 months if no event was recorded.

We used appropriate survival analysis techniques to calculate event rates. ${ }^{8}$ We assessed differences between groups in the cumulative probability of the primary end point or of all cardiovascular events by using the log rank test. We used Cox's proportional hazards models to determine the effects of clinical and investigative variables on the occurrence of death or non-fatal myocardial infarction in both univariate and multivariate analysis. Starting with clinical variables, we did stepwise regression (using entry/removal $\mathrm{P}$ value $=0.15$ ) to determine the factors predictive of death or infarction during follow-up. Stepwise selection may lead to unstable results if the variables considered for inclusion in the final model are highly correlated. To avoid this, we used both forward and backward methods, as these (if leading to inconsistent selections) would indicate the presence of colinearity and therefore potentially inappropriate multivariate models. We developed models separately for clinical and investigative parameters and then for a combination of clinical and investigative parameters. We refitted the final model for all patients without missing values for the variables selected. We used likelihood ratio tests to test the predictors' significance and to assess presence of departure from a linear effect for continuous variables.

To develop a scoring system for predicting the probability of death or infarction during the first year after presentation that was based only on objective information generally available to clinicians and not on whether a test was done, we developed a further multivariate model without the stress test done/not done variable, as outlined in appendix B on bmj.com. We assessed the performance of the model by calculating the Harrell's C-statistic (comparable to the area under the receiver operating characteristics curve). ${ }^{9}$ We used Stata version 9 statistical software for all analyses.

\section{Results}

From March 2002 to December 2002, 3779 patients with stable angina were enrolled into the study. Vital status during follow-up was ascertained in $3259(86 \%)$ patients, and data were suitable for survival analysis for the primary outcome of interest, which included non-fatal myocardial infarction, in 3031. The median duration of follow-up was 13 (interquartile range 12-15) months. No substantial differences existed between the patients with and without follow-up information in terms of clinical characteristics (table 1) or regional distribution. Thus the survival analysis results, which are based on the 3031 patients with follow-up data, can be treated as indicative of the overall survival experience. The population was relatively young-mean age 61 years-and $58 \%$ were male. Most patients had mild to moderate symptoms
Table 1 Baseline clinical characteristics of patients with and without completed clinical follow-up. Values are numbers (percentages) unless stated otherwise

\begin{tabular}{|c|c|c|c|}
\hline Variable & $\begin{array}{l}\text { Follow-up } \\
\text { incomplete }(n=748)\end{array}$ & $\begin{array}{c}\text { Follow-up } \\
\text { complete }(\mathrm{n}=3031)\end{array}$ & $P$ value* \\
\hline Mean (SD) age (years) & $61 \quad(11)(n=742)$ & $61(11)(\mathrm{n}=2989)$ & 0.85 \\
\hline Female sex & $311 / 748$ (42) & 1271/3031 (42) & 0.83 \\
\hline Symptom severity (CCS class): & $\mathrm{n}=706$ & $\mathrm{n}=2766$ & \multirow{4}{*}{0.15} \\
\hline Class I & $251(36)$ & $1096(40)$ & \\
\hline Class II & $360(51)$ & $1331(48)$ & \\
\hline Class III & $95(13)$ & $339(12)$ & \\
\hline Duration of angina symptoms: & $\mathrm{n}=706$ & $\mathrm{n}=2814$ & \multirow{5}{*}{0.18} \\
\hline$<1$ month & $4(<1)$ & $48(2)$ & \\
\hline 1-5 months & $365(52)$ & $1494(53)$ & \\
\hline 6-11 months & $155(22)$ & $585(21)$ & \\
\hline$\geq 12$ months & $182(26)$ & $687(24)$ & \\
\hline Previous MI (>1 year before) & $13 / 445(3)$ & $117 / 2456(5)$ & 0.08 \\
\hline Peripheral vascular disease & $51 / 748(7)$ & $216 / 3031(7)$ & 0.76 \\
\hline Previous TIA or CVA & $46 / 748$ (6) & $151 / 3031$ (5) & 0.20 \\
\hline Respiratory disease & $66 / 748(8)$ & $247 / 3031$ (8) & 0.54 \\
\hline Renal failure & $7 / 748$ (1) & $47 / 3031$ (2) & 0.20 \\
\hline Chronic inflammatory conditions & $16 / 748$ (3) & $90 / 3031$ (3) & 0.22 \\
\hline Peptic ulcer disease & $47 / 748$ (6) & 197/3031 (6) & 0.79 \\
\hline Malignancy & $14 / 748$ (2) & $47 / 3031$ (2) & 0.53 \\
\hline Diabetes & $122 / 713(17)$ & $530 / 2953(18)$ & 0.59 \\
\hline Hypertension & 458/727 (63) & 1809/2949 (61) & 0.39 \\
\hline Smoking status: & $\mathrm{n}=725$ & $\mathrm{n}=2828$ & \multirow{3}{*}{0.71} \\
\hline Ex-smoker & $220(30)$ & $844(30)$ & \\
\hline Current smoker & $173(24)$ & $646(23)$ & \\
\hline Hyperlipidaemia & $391 / 629$ (62) & $1452 / 2545$ (57) & 0.02 \\
\hline Signs of heart failure & $75 / 747$ (10) & $221 / 3022(7)$ & 0.01 \\
\hline Mean (SD) systolic BP (mm Hg) & $144(22)(\mathrm{n}=748)$ & $145(21)(n=3001)$ & 0.43 \\
\hline Mean (SD) body mass index & $28(4)(n=668)$ & $28(4) \quad(n=2738)$ & 0.79 \\
\hline Drugs at baseline: & $\mathrm{n}=748$ & $n=3031$ & \\
\hline Aspirin & $374(50)$ & $1602(47)$ & 0.16 \\
\hline Statin & $184(25)$ & $1429(21)$ & 0.04 \\
\hline$\beta$ blocker & $262(35)$ & $1142(38)$ & 0.18 \\
\hline
\end{tabular}

$\mathrm{BP}=$ blood pressure; $\mathrm{CCS}=$ Canadian Cardiology Society; $\mathrm{CVA}=$ cerebrovascular event; $\mathrm{MI}=$ myocardial infarction; TIA=transient ischaemic attack.

${ }^{*}$ For differences in proportions or means between patients with and without complete follow-up data.

of angina for six months or less before presentation to a cardiologist, although only 48 (1.7\%) patients had symptoms for less than one month before cardiology assessment.

\section{Confirmation of coronary disease}

Coronary angiography was done at least once during follow-up in $1253(41 \%)$ patients. At the end of the follow-up period, approximately one third $(\mathrm{n}=994)$ of patients had had coronary disease confirmed angiographically and a further third $(n=1023)$ had negative investigations. One sixth of patients had no definitive diagnostic test to confirm the presence or absence of coronary disease (table 2).

Table 2 Coronary disease status according to level of diagnostic investigation completed at end of follow-up ( $n=3031)$.

\begin{tabular}{lc} 
Coronary disease status & No (\%) \\
\hline $\begin{array}{l}\text { Confirmed coronary artery disease (obstructive coronary disease defined } \\
\text { as at least } 50 \% \text { stenosis of an epicardial vessel confirmed at coronary } \\
\text { angiography) }\end{array}$ & 994 (33) \\
\hline $\begin{array}{l}\text { Positive non-invasive tests (positive non-invasive tests without } \\
\text { angiography) }\end{array}$ & 486 (16) \\
\hline $\begin{array}{l}\text { Incomplete investigation (no functional assessment or angiography, or } \\
\text { inconclusive result from functional assessment) }\end{array}$ & 528 (17) \\
\hline $\begin{array}{l}\text { Negative investigation (negative coronary angiography or, in the absence } \\
\text { of angiography, negative non-invasive tests) }\end{array}$ & 1023 (34) \\
\hline
\end{tabular}


Table 3 Major clinical events occurring during follow-up in the overall population and in patients with confirmed coronary disease

\begin{tabular}{|c|c|c|c|c|}
\hline \multirow[b]{2}{*}{ End point } & \multicolumn{2}{|c|}{ Stable angina $(\mathrm{n}=3031)$} & \multicolumn{2}{|c|}{ Stable angina with confirmed CAD ( $n=994)$} \\
\hline & No of events & $\begin{array}{c}\text { Event rate }(95 \% \mathrm{Cl}) \text { per } 100 \text { patient } \\
\text { years }\end{array}$ & No of events & Event rate $(95 \% \mathrm{CI})$ per 100 patient years \\
\hline Death* $^{*}$ & 50 & 1.5 (1.1 to 1.9$)$ & 19 & 1.8 (1.1 to 2.8$)$ \\
\hline Non-cardiovascular death & $14(28 \%)$ & & $2(11 \%)$ & \\
\hline Non-fatal myocardial infarction & 48 & $1.4(1.1$ to 1.9$)$ & 34 & 3.2 (2.3 to 4.4$)$ \\
\hline Death and non-fatal myocardial infarction & 93 & 2.3 (1.9 to 2.8$)$ & 50 & 3.9 (2.9 to 5.1$)$ \\
\hline Cerebrovascular event & 34 & $1.1(0.8$ to 1.5$)$ & 15 & 1.6 (1.0 to 2.6$)$ \\
\hline Heart failure & 49 & 1.5 (1.1 to 2.0$)$ & 20 & 2.1 (1.3 to 3.2$)$ \\
\hline Unstable angina & 164 & $5.2(4.4$ to 6.0$)$ & 114 & 12.1 (10.1 to 14.6$)$ \\
\hline All cardiovascular events $\dagger$ & 328 & $10.3(9.3$ to 11.5$)$ & 207 & 21.9 (19.1 to 25.2 ) \\
\hline
\end{tabular}

$\mathrm{CAD}=$ coronary artery disease.

${ }^{*}$ Of 50 deaths, the cause of death was classified as unknown or missing in six and cardiac or cardiovascular in 29.

tCardiovascular death, non-fatal myocardial infarction, unstable angina, heart failure, stroke, and emergency revascularisation.

\section{Clinical events during follow-up}

Table 3 shows the numbers of individual clinical events and the annual rates of clinical events in the overall study population and the subgroup with confirmed coronary disease. The incidence of death or infarction was significantly greater $(\mathrm{P}<0.001)$ in patients with confirmed coronary disease than in those with negative investigations or positive non-invasive tests without angiographic confirmation of disease (fig 1). However, patients who had no investigation, or inconclusive results on non-invasive investigation that were not pursued further, had a rate of death or infarction-4.1/100 patient years (95\% confidence interval 2.7 to 6.0)- that was similar to that in the population with confirmed coronary disease. Non-cardiovascular death did not seem to contribute a disproportionate number of these deaths, accounting for only $7 / 21(33 \%)$ deaths. This was a similar proportion to that seen in the group with positive non-invasive tests $(1 / 3,33 \%)$ and less than the proportion seen in the group with negative investigations $(4 / 7,57 \%)$, although it was higher than the proportion seen in the group with confirmed coronary artery disease $(2 / 19,11 \%)$

\section{Clinical and investigative factors predictive of adverse outcome}

Table 4 shows the risk of death or myocardial infarction associated with baseline clinical characteristics and results of investigations. Previous myocardial infarction, signs of heart failure, or a past history of diabetes, hypertension, or any comorbidity were significant predictors of adverse outcome, as were increasing severity of symptoms and shorter duration of symptoms. Resting electrocardiographic abnormalities $(Q$ wave or ST/T wave changes) were associated with approximately double the risk of death or myocardial infarction, but positive non-invasive stress test results were not significantly associated

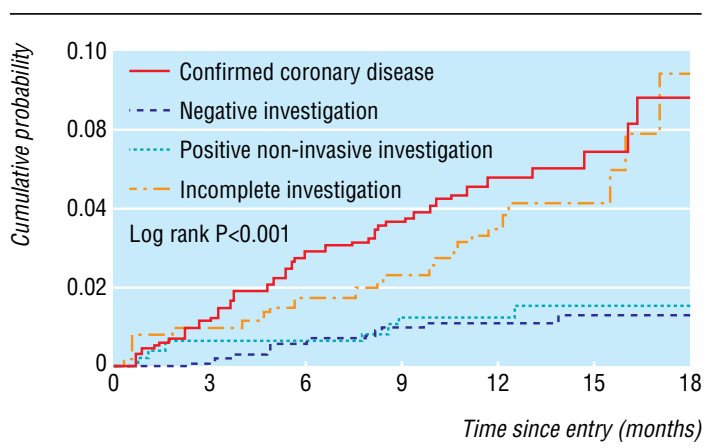

Fig 1 Cumulative probability of death or non-fatal myocardial infarction during follow-up in patients with stable angina, according to diagnostic level of confirmation of coronary disease with adverse outcome. As the numbers of patients with stress imaging techniques were small, we created a new indicator to summarise the information on all forms of functional assessment (exercise electrocardiogram, stress echocardiogram, or perfusion). Not having had any functional assessment was an indicator of substantially increased risk, as was abnormal left ventricular function assessed by echocardiography.

Table 4 Unadjusted hazard ratio of death or myocardial infarction associated with clinical and investigative parameters in general population with stable angina $(\mathrm{n}=3031)$

\begin{tabular}{|c|c|c|}
\hline & Hazard ratio $(95 \% \mathrm{Cl})$ & P value* \\
\hline \multicolumn{3}{|l|}{ Clinical variables } \\
\hline Age (per 1 year increment) & 1.03 (1.01 to 1.05$)$ & 0.001 \\
\hline Sex (female $v$ male) & 1.19 (0.79 to 1.79) & 0.40 \\
\hline Diabetes & 2.40 (1.55 to 3.70$)$ & $<0.001$ \\
\hline Hypertension & 2.12 (1.29 to 3.48$)$ & 0.002 \\
\hline Hyperlipidaemia & 1.00 (0.63 to 1.58) & 0.99 \\
\hline Ever smoked & 1.53 (1.00 to 2.36$)$ & 0.05 \\
\hline Previous myocardial infarction & 3.24 (1.72 to 6.13$)$ & 0.002 \\
\hline Comorbidity & 2.98 (1.98 to 4.52) & $<0.001$ \\
\hline \multicolumn{3}{|l|}{ Symptom severity: } \\
\hline Class II versus class I & 2.34 (1.37 to 4.00$)$ & \multirow{2}{*}{0.0002} \\
\hline Class III versus class I & 3.44 (1.80 to 6.55$)$ & \\
\hline Symptom duration $>6$ months & 0.60 (0.39 to 0.94$)$ & 0.03 \\
\hline Signs of heart failure & 2.67 (1.56 to 4.57$)$ & 0.001 \\
\hline Body mass index $>30$ & 0.82 (0.49 to 1.37) & 0.43 \\
\hline Tertiary education & 0.78 (0.40 to 1.52) & 0.46 \\
\hline \multicolumn{3}{|l|}{ Investigative variables } \\
\hline Left bundle branch block & 1.50 (0.66 to 3.43$)$ & 0.34 \\
\hline$\overline{Q \text { wave }}$ & 2.37 (1.38 to 4.06$)$ & 0.002 \\
\hline ST or T wave changes & 2.26 (1.50 to 3.41$)$ & $<0.001$ \\
\hline Ischaemic ECG changes† & 2.27 (1.50 to 3.43 ) & $<0.001$ \\
\hline \multicolumn{3}{|l|}{ Result of individual stress tests: } \\
\hline Positive exercise ECG¥ $(\mathrm{n}=2299)$ & 1.44 (0.80 to 2.61) & 0.22 \\
\hline $\begin{array}{l}\text { Positive stress echocardiogram } \neq \\
(\mathrm{n}=119)\end{array}$ & 1.24 (0.24 to 6.40$)$ & 0.80 \\
\hline Positive perfusion scan $\ddagger(n=420)$ & 3.55 (0.77 to 16.47) & 0.07 \\
\hline \multicolumn{3}{|l|}{ Result of any stress test§: } \\
\hline Positive test & 1.50 (0.82 to 2.73) & $<0.0001$ \\
\hline No test done & 4.42 (2.50 to 7.82$)$ & \\
\hline \multicolumn{3}{|l|}{ Echocardiography (before events): } \\
\hline Abnormal left ventricular function? & 5.21 (3.19 to 8.49) & $<0.001$ \\
\hline
\end{tabular}

ECG=electrocardiogram.

*Likelihood ratio test for heterogeneity among category specific rates (hazards) for variables categories.

tOne or more of ST or T wave changes, $Q$ waves, or left bundle branch block. $\neq$ Versus negative or inconclusive.

SExercise ECG, stress echocardiogram, or perfusion scan; versus negative test

१Moderate or poor left ventricular function detected on echocardiography, provided test was done before events occurring during follow-up. 
Table 5 Clinical and investigative parameters independently predictive of death or myocardial infarction, determined by using stepwise selection procedures in general population with stable angina

\begin{tabular}{|c|c|c|}
\hline & Hazard ratio $(95 \% \mathrm{Cl})$ & $P$ value* \\
\hline \multicolumn{3}{|l|}{ Clinical variables $(n=2183)$} \\
\hline Comorbidity & 2.41 (1.49 to 3.91$)$ & $<0.001$ \\
\hline Signs of heart failure & $1.62(0.85$ to 3.07$)$ & 0.14 \\
\hline Previous myocardial infarction & 2.19 (1.08 to 4.42$)$ & 0.03 \\
\hline Diabetes & $2.03(1.25$ to 3.31$)$ & 0.004 \\
\hline Symptom duration $>6$ months & 0.54 (0.33 to 0.87$)$ & 0.01 \\
\hline \multicolumn{3}{|l|}{ Symptom severity: } \\
\hline Class II versus class I & 1.95 (1.07 to 3.54$)$ & \multirow{2}{*}{0.005} \\
\hline Class III versus class I & $2.65(1.29$ to 5.50$)$ & \\
\hline \multicolumn{3}{|l|}{ Investigative variables $(\mathrm{n}=\mathbf{2 9 6 3 )}$} \\
\hline \multicolumn{3}{|l|}{ Stress testing: } \\
\hline Positive test & $1.43(0.76$ to 2.70$)$ & \multirow{2}{*}{0.0001} \\
\hline No stress test done & 3.78 (2.04 to 7.00$)$ & \\
\hline \multicolumn{3}{|l|}{ Echocardiography: } \\
\hline Abnormal left ventricular function & 2.57 (1.62 to 4.08$)$ & $<0.0001$ \\
\hline \multicolumn{3}{|l|}{ Electrocardiography: } \\
\hline ST or T wave changes & 1.63 (1.06 to 2.50$)$ & 0.03 \\
\hline \multicolumn{3}{|c|}{ Combined clinical and investigative variables $(n=2528)$} \\
\hline Comorbidity & 2.25 (1.43 to 3.56$)$ & 0.0008 \\
\hline Diabetes & 1.95 (1.22 to 3.11$)$ & 0.007 \\
\hline Previous myocardial infarction & - & \\
\hline Symptoms $>6$ months & 0.48 (0.30 to 0.77$)$ & 0.002 \\
\hline \multicolumn{3}{|l|}{ Symptom severity: } \\
\hline Class II versus class I & 1.76 (1.00 to 3.09$)$ & \multirow{2}{*}{0.05} \\
\hline Class III versus class I & 2.18 (1.10 to 4.33$)$ & \\
\hline ST or T wave changes & 1.56 (0.99 to 2.45$)$ & 0.05 \\
\hline \multicolumn{3}{|l|}{ Stress test: } \\
\hline Positive stress test result & 1.29 (0.63 to 2.67) & \multirow{2}{*}{$<0.0001$} \\
\hline No stress test done & 3.48 (1.71 to 7.07$)$ & \\
\hline Abnormal left ventricular function & 2.11 (1.29 to 3.46$)$ & 0.004 \\
\hline
\end{tabular}

* Likelihood ratio test for heterogeneity among category specific rates (hazards) for variables categories.

Stepwise regression selected comorbidity, diabetes, recent onset of symptoms, more severe symptoms, ST or T wave abnormalities on the resting electrocardiogram, not having any stress test done, and abnormal ventricular function as the variables most predictive of outcome (table 5). Age and sex were not significant predictors when forced into the model. Although age had a linear effect that was significant when examined on its own (table 4), its strong association with most of the other variables led to its lack of significance in the multivariate model (highly significant association with all variables except "ST or T wave change").

\section{Development of a clinical risk score for patients with stable} angina

As non-performance of a test is not an objective measure of a patient but can be influenced by many physician related and non-clinical factors, we used a further stepwise selection process to consider only the results of non-invasive investigations that had been done. A positive versus negative or inconclusive non-invasive stress test result was not selected as a significant predictor of outcome when combined with information from echocardiography and resting electrocardiography. Thus in the model developed to derive the clinical risk score the final predictors of death or myocardial infarction were comorbidity, diabetes, severity of symptoms, duration of symptoms, resting electrocardiogram abnormalities, and abnormal ventricular function. Using each of these parameters a risk score can be calculated according to the weighted scores shown in table 6 . This score can then be used to estimate visually the probability of
Table 6 Score sheet to calculate risk score for patients presenting with stable angina

\begin{tabular}{|c|c|c|}
\hline Risk factor & Score contribution & Individual's score \\
\hline \multicolumn{3}{|l|}{ Comorbidity* } \\
\hline No & 0 & \\
\hline Yes & 86 & \\
\hline \multicolumn{3}{|l|}{ Diabetes } \\
\hline No & 0 & \\
\hline Yes & 57 & \\
\hline \multicolumn{3}{|l|}{ Angina score } \\
\hline Class I & 0 & \\
\hline Class II & 54 & \\
\hline Class III & 91 & \\
\hline \multicolumn{3}{|c|}{ Duration of symptoms } \\
\hline$\geq 6$ months & 0 & \\
\hline$<6$ months & 80 & \\
\hline \multicolumn{3}{|c|}{ Abnormal ventricular function } \\
\hline No & 0 & \\
\hline Yes & 114 & \\
\hline \multicolumn{3}{|c|}{ ST depression or T wave inversion on resting electrocardiogram } \\
\hline No & 0 & \\
\hline \multirow[t]{2}{*}{ Yes } & 34 & \\
\hline & & Total= \\
\hline
\end{tabular}

${ }^{*}$ One or more of previous cerebrovascular event; hepatic disease defined as chronic hepatitis or cirrhosis, or other hepatic disease causing elevation of transaminases more than three times upper limit of normal; peripheral vascular disease defined as claudication either at rest or on exertion, amputation for arterial vascular insufficiency, vascular surgery (reconstruction or bypass) or angioplasty to the extremities, documented aortic aneurysm, or non-invasive evidence of impaired arterial flow; chronic renal failure defined as chronic dialysis or renal transplantation or serum creatinine greater than $200 \mu \mathrm{mol} / /$; chronic respiratory disease defined as a diagnosis previously made by physician or patient receiving bronchodilators or $\mathrm{FEV}_{1}<75 \%$, arterial $\mathrm{pO}_{2}<60 \%$, or arterial $\mathrm{pCO}_{2}>50 \%$ predicted in previous studies; chronic inflammatory conditions defined as a diagnosis of rheumatoid arthritis, systemic lupus erythematosis or other connective tissue diseases, polymyalgia rheumatica, and so on; malignancy defined as a diagnosis of malignancy within a year or active malignancy.

death or myocardial infarction from the plot in figure 2 or (using the closest rounded figure) to read the estimated probability from table 7. Applying the model developed on $75 \%$ of the population to the remaining $25 \%$ of the population gave a C-statistic for the angina score to predict outcome of 0.74 .

\section{Discussion}

The Euro heart survey of stable angina population differs from a general selection of people with angina in the community, many of whom may not have a diagnosis, and differs from the overall primary care angina population in that they have been selected for specialist assessment. However, the population is compara-

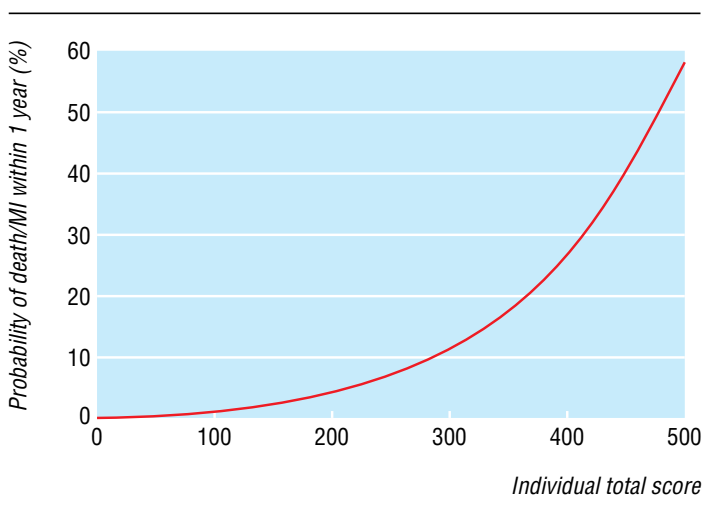

Fig 2 Plot to assign estimated probability of death or non-fatal myocardial infarction within one year of presentation according to combination of clinical and investigative features in patients with stable angina (corresponding to scoring system in table 7). MI=myocardial infarction 
Table 7 Estimated probability of death or non-fatal myocardial infarction over one year corresponding to selected values of the individual scores

\begin{tabular}{|c|c|}
\hline Score* & Estimated probability of death/myocardial infarction in 1 year (\%) \\
\hline 0 & 0.57 \\
\hline$\overline{10}$ & 0.63 \\
\hline 20 & 0.70 \\
\hline 30 & 0.77 \\
\hline 40 & 0.85 \\
\hline 50 & 0.94 \\
\hline 60 & 1.04 \\
\hline 70 & 1.14 \\
\hline 80 & 1.26 \\
\hline 90 & 1.40 \\
\hline 100 & 1.54 \\
\hline 110 & 1.70 \\
\hline$\overline{120}$ & 1.88 \\
\hline$\overline{130}$ & 2.08 \\
\hline$\overline{140}$ & 2.29 \\
\hline 150 & 2.53 \\
\hline 160 & 2.79 \\
\hline 170 & 3.08 \\
\hline 180 & 3.39 \\
\hline 190 & 3.75 \\
\hline 200 & 4.13 \\
\hline 210 & 4.56 \\
\hline 220 & 5.03 \\
\hline 230 & 5.54 \\
\hline 240 & 6.11 \\
\hline 250 & 6.73 \\
\hline 260 & 7.41 \\
\hline 270 & 8.15 \\
\hline 280 & 8.97 \\
\hline 290 & 9.86 \\
\hline 300 & 10.84 \\
\hline 310 & 11.91 \\
\hline 320 & 13.08 \\
\hline 330 & 14.35 \\
\hline 340 & 15.74 \\
\hline 350 & 17.24 \\
\hline 360 & 18.87 \\
\hline 370 & 20.64 \\
\hline 380 & 22.54 \\
\hline 390 & 24.60 \\
\hline 400 & 26.80 \\
\hline 410 & 29.16 \\
\hline 420 & 31.69 \\
\hline 430 & 34.37 \\
\hline 440 & 37.21 \\
\hline 450 & 40.21 \\
\hline 460 & 43.36 \\
\hline 470 & 46.65 \\
\hline
\end{tabular}

*Log hazard ratios multiplied by 100 .

tively less highly selected than those in randomised controlled trials or angiographic registries.

\section{Comparisons with clinical trial populations with stable angina}

The annual incidence of death in the survey was $1.5 \%$, and the incidence of non-fatal myocardial infarction was $1.4 \%$. In the subgroup with proved coronary disease these rates were $1.8 \%$ and $3.2 \%$. Estimates of annual mortality from modern clinical trials of secondary prevention, antianginal treatment, or revascularisation range from $0.9 \%$ to $1.7 \%,{ }^{10-13}$ with a higher mortality in populations with more severe symptoms..$^{10}$ Reported annual incidences of non-fatal myocardial infarction range from $1.1 \%$ to $1.5 \% .^{11}{ }^{12}$

\section{Determining prognosis in an individual}

The process of assessing prognosis in stable angina serves several purposes: to facilitate an informed response to the patient's own queries and answer specific questions from employers and insurers, to determine the need for further investigation or specialist opinion, and to assist in choosing appropriate treatment.

On the whole the features identified in this study as predicting adverse outcome in the population with stable angina are in keeping with previous observations in registry data. ${ }^{14}$ Importantly, negative investigations, either invasive or noninvasive, identify a low risk population. Even with the relatively short follow-up in this survey, the prognostic importance of comorbidity is substantial, of the same order as the impact of abnormal ventricular function. This has also recently been shown in a study from the Duke database ${ }^{16}$ A further important finding is that, in this population with largely uncomplicated stable angina (few patients had evidence of heart failure or previous myocardial infarction), the severity of angina, as measured by the simple and widely used Canadian Cardiovascular Society classification system, was a useful prognostic indicator.

Angina scores incorporating the pattern of occurrence of angina and the severity of symptoms unresponsive to medical treatment or recurrent symptoms after revascularisation have previously been shown to predict prognosis in the stable angina population, ${ }^{17}{ }^{18}$ but the predictive value lessens with longer follow-up and is greatest in patients with preserved ventricular function. The strength of angina symptoms in predicting prognosis in this population may be related to the low prevalence of pronounced ventricular dysfunction, the short duration of follow-up, and the fact that most of these patients were already on antianginal medications before presentation to a cardiologist.

\section{Risk prediction score}

Several widely available multiple risk factors equations exist to calculate the absolute risk of developing coronary or cardiovascular disease in patients without established disease. ${ }^{34}$ However, such risk scores do not apply to a population with symptoms. Although several scores have been developed to predict the presence of coronary disease by using clinical or exercise variables or their combination, ${ }^{19}{ }^{20}$ prognostic scores are comparatively few and applicability is limited by restriction of the population studied to those who can exercise. ${ }^{2122}$ A modified version of the Framingham risk equation exists, which has been adapted for use in patients with pre-existing cardiovascular disease, ${ }^{23}$ but this does not allow discrimination between initial manifestations of coronary disease or presenting symptoms. Cumulative data from single institution databases, such as the Duke database, have also been used to synthesise nomograms to assign absolute probabilities of coronary disease and mortality given various combinations of data from clinical assessment, non-invasive testing, and coronary angiography. ${ }^{23}$ However, these tools were developed in populations assessed up to 30 years ago, are not specific to a stable angina population, and may not be widely applicable.

The Euro heart angina score is simple and objective and allows discrimination between an extremely low risk group (annual rate of death and non-fatal infarction of $<0.5 \%$ ) and those at high risk over a one year period, in a population with a clinical diagnosis of stable angina. The C-statistic for survival derived from a physician's initial assessment in the Duke database was 0.82 when applied to a later cohort from Duke. ${ }^{24}$ Thus the predictive accuracy of this score is comparable to that 


\section{What is already known on this topic}

Contemporary data on clinical outcome in stable angina outside randomised controlled trials are lacking, and in recent clinical trials the annual mortality ranges from $0.9 \%$ to $2.9 \%$

Previous reports of the factors of prognostic importance in stable coronary disease were drawn from highly selected populations and predate modern drug management

\section{What this study adds}

In this contemporary evaluation of the prognosis associated with stable angina, the incidence of death and myocardial infarction was $2.3 / 100$ patient years

Comorbidity, diabetes, severity of angina, shorter duration of symptoms, left ventricular dysfunction, and ST changes on the resting electrocardiogram independently predicted outcome

A simple score involving these six characteristics can be used to estimate the probability of death or myocardial infarction in the year after presentation with stable angina

of older predictive models but is more relevant to a contemporary population.

\section{Conclusions}

In patients presenting with stable angina, simple clinical features are strongly predictive of prognosis. A low risk population may be effectively identified by negative investigations, and those who are not investigated constitute a high risk group. By identifying the features most predictive of adverse outcome we have been able to construct a simple scoring system to calculate an estimate of the one year probability of death or non-fatal myocardial infarction in patients with stable angina.

We are indebted to the Euro heart survey investigators who collect and submit data on a voluntary basis and the Euro heart survey team members who have contributed to this survey.

Contributors: $\mathrm{CAD}$ was involved in the design and running of the trial, planning and performance of the analysis, interpretation of the data, and writing the manuscript. BDeS and FC were involved in data analysis and critical review of the manuscript.JLLS, LT, FD, ND, EB, DM, DJ, AG, WR, KT, $\mathrm{FV}$, and KMF were involved in design of the trial and critical review of the manuscript. KMF is the guarantor.

Funding: Servier Laboratories was the principal financial sponsor for the study. The funding source had no role in study design, data collection, analysis, or interpretation.

Competing interests: None declared.

Ethical approval: Ethical approval was sought in each country in accordance with local practice. In the UK multicentre research ethics committee was granted; in other countries the local ethics committee or relevant authority granted approval.

1 Ford ES, Giles WH, Croft JB. Prevalence of nonfatal coronary heart disease among American adults. Am Heart J 2000; 139:371-7.

2 Cosin J, Asin E, Marrugat J, Elosua R, Aros F, de los Reyes M, et al. Prevalence of angina pectoris in Spain. Eur J Epidemiol 1999;15:323-30.

3 Gectoris in Spain. Eur J Epidemiol 1999;15:323-30. lar risk by use of multiple-risk-factor assessment equations: a statement for healthcare professionals from the American Heart Association and the American College of Cardiology. Circulation 1999;100:1481-92

4 Hense HW. Risk factor scoring for coronary heart disease. BMJ 2003;29;327:1238-9.

5 Brindle P, Emberson J, Lampe F, Walker M, Whincup P, Fahey T, et al. Predictive accuracy of the Framingham coronary risk score in British men: prospective cohort study BMJ 2003;327:1267

6 Empana JP, Ducimetiere P, Arveiler D, Ferrieres J, Evans A, Ruidavets JB, et al. Are the Framingham and PROCAM coronary heart disease risk functions applicable to different European populations? The PRIME study. Eur Heart J 2003;24:1903-11.
7 Daly CA, Clemens F, Lopez Sendon JL, Tavazzi L, Boersma E, Danchin N, et al. The clinical characteristics and investigations planned in patients with stable angina presenting to cardiologists in Europe, from the Euro heart survey of stable angina. Eur Heart J 2005;26:996-1010.

8 Collett D. Modelling survival data in medical research. London: Chapman and Hall, 1994

9 Harrell FE Jr, Lee KL, Mark DB. Multivariable prognostic models: issues in developing models, evaluating assumptions and adequacy, and measuring and reducing errors. Stat Med 1996;15:361-87.

10 Effect of nicorandil on coronary events in patients with stable angina: the impact of nicorandil in angina (IONA) randomised trial. Lancet 2002;359:1269-75.

11 Fox KM. Efficacy of perindopril in reduction of cardiovascular events among patients with stable coronary artery disease: randomised, double-blind, placebo-controlled, multicentre trial (the EUROPA study). Lancet 2003;362:782-8.

12 Braunwald E, Domanski MJ, Fowler SE, Geller NL, Gersh BJ, Hsia J, et al. Angiotensinconverting-enzyme inhibition in stable coronary artery disease. $N$ Engl $J$ Med 2004;351:2058-68.

13 Henderson RA, Pocock SJ, Clayton TC, Knight R, Fox KA, Julian DG, et al. Seven-year outcome in the RITA-2 trial: coronary angioplasty versus medical therapy. $J$ Am Coll Cardiol 2003;42:1161-70.

14 Mock MB, Rinqvist I, Fisher L, Davis K, Chaitman B, Kouchoukos N, et al. Survival of medically treated patients in the coronary artery surgery study (CASS) registry. Circulation 1982;66:562-8.

15 Hammermeister KE, De Rouen TA, Dodge HT. Variables predictive of survival in patients with coronary disease: selection by univariate and multivariate analysis from the clinical, exercise arteriographic, and quantitative angiographic evaluations. Circulation 1979;59:421-30.

16 Sachdev M, Sun JL, Tsiatis AA, Nelson CL, Mark DB, Jollis JG. The prognostic importance of comorbidity for mortality in patients with stable coronary artery disease. J Am Coll Cardiol 2004;43:576-82.

17 Califf RM, Mark DB, Harrell FE Jr, Hlatky MA, Lee KL, Rosati RA, et al. Importance of clinical measures of ischemia in the prognosis of patients with documented coronary artery disease. J Am Coll Cardiol 1988;11:20-6.

18 Hultgren HN, Peduzzi P. Relation of severity of symptoms to prognosis in stable angina pectoris. Am J Cardiol 1984;54:988-93.

19 Pryor DB, Shaw L, Harrell FE Jr, Lee KL, Hlatky MA, Mark DB, et al. Estimating the Pryor DB, Shaw L, Harrell FE Jr, Lee KL, Hlatky MA, Mark DB, et al.
likelihood of severe coronary artery disease. Am J Med 1991;90:553-62.

20 Yamada H, Do D, Morise A, Atwood JE, Froelicher V. Review of studies using multivariable analysis of clinical and exercise test data to predict angiographic coronary artery disease. Prog Cardiovasc Dis 1997;39:457-81.

21 Mark DB, Hlatky MA, Harrell FE, Lee KL, Califf RM, Pryor DB. Exercise treadmill score for predicting prognosis in coronary disease. Ann Intern Med 1987;106:793-800.

22 Prakash M, Myers J, Froelicher VF, Marcus R, Do D, Kalisetti D, et al. Clinical and exercise test predictors of all-cause mortality: results from $>6,000$ consecutive referred male patients. Chest 2001;120:1003-13.

23 Califf RM, Armstrong PW, Carver JR, D’Agostino RB, Strauss WE. 27th Bethesda Conference: matching the intensity of risk factor management with the hazard for coronary
disease events. Task Force 5: stratification of patients into high, medium and low risk disease events. Task Force 5: stratification of patients into high, medium and low risk
subgroups for purposes of risk factor management. J Am Coll Cardiol 1996;27:1007-19. 24 Pryor DB, Shaw L, McCants CB, Lee KL, Mark DB, Harrell FE, et al. Value of the history and physical in identifying patients at increased risk for coronary artery disease. Ann Intern Med 1993;118:81-90.

(Accepted 8 November 2005)

doi 10.1136/bmj.38695.605440.AE

Royal Brompton Hospital, London SW3 6NP

Caroline A Daly clinical research fellow

Kim M Fox professor of cardiology

London School of Hygiene and Tropical Medicine, London

Bianca De Stavola senior lecturer in clinical epidemiology

Felicity Clemens medical statistician

Hospital Universitario Gregorio Maranon, Madrid, Spain

Jose L Lopez Sendon professor of cardiology

Policlinico S Matteo, Pavia, Italy

Luigi Tavazzi professor of cardiology

Erasmus Medical Centre, Rotterdam, Netherlands

Eric Boersma clinical epidemiologist

Hopital Europeen Georges Pompidou, Paris, France

Nicholas Danchin cardiologist

Hopital Cardiovasculaire et Pneumologique Louis Pradel, Lyons, France

Francois Delahaye cardiologist

Herzzentrum Luwigshafen, Ludwigshafen, Germany

Anselm Gitt cardiologist

University of Newcastle upon Tyne, Newcastle upon Tyne

Desmond Julian professor of cardiology

Adelaide and Meath incorporating National Children's Hospital, Dublin, Ireland

David Mulcahy consultant cardiologist

Institute of Cardiology, Warsaw, Poland

Witold Ruzyllo professor of cardiology

Aarhus University Hospital, Aarhus, Denmark

Kristian Thygesen professor of cardiology

University Medical Centre St Radboud, Nijmegen, the Netherlands

Freek Verheugt professor of cardiology

Correspondence to: C A Daly caroline.daly@imperial.ac.uk 